\title{
Exorcising the Positivist Ghost in the Priority-Setting Machine: NICE and the Demise of the 'Social
}

Value Judgement'

Victoria Charlton ${ }^{1}$ and Albert Weale ${ }^{2}$

${ }^{1}$ Department of Global Health \& Social Medicine, King's College London; ${ }^{2}$ Department of Political Science, University College London

\section{Corresponding Author:}

\section{Victoria Charlton}

Department of Global Health \& Social Medicine

King's College London

40 Aldwych, London WC2B 4BG

United Kingdom

E-mail: victoria.charlton@kcl.ac.uk

Telephone: (+44) 7813161515

ORCID: 0000-0002-7407-2627

\section{ABSTRACT}

The National Institute for Health and Care Excellence (NICE), the UK's primary healthcare priority-setting body, has traditionally described its decisions as being informed by 'social value judgements' about how resources should be allocated across society. This article traces the intellectual history of this term and suggests that, in NICE's adoption of the idea of the 'social value judgement', we are hearing the echoes of welfare economics at a particular stage of its development, when logical positivism provided the basis for thinking about public policy choice. As such, it is argued that the term offers an overly simplistic conceptualisation of NICE's normative approach and contributes to a situation in which NICE finds itself without the necessary language fully and accurately to articulate its basis for decision-making. It is suggested that the notion of practical public reasoning, based on reflection about coherent principles of action, might provide a better characterisation of the enterprise in which NICE is, or hopes to be, engaged. 


\section{Introduction}

The National Institute for Health and Care Excellence (NICE) is the UK's primary healthcare priority-setting body and, as such, is responsible for making difficult decisions that can have profound consequences for the quality and comprehensiveness of the care provided by the NHS. These are inherently normative decisions and NICE has traditionally described them as being informed by a number of 'social value judgements'. But what is is a 'social value judgement' and how adequate a conceptualisation can this term offer for the normative considerations faced by a body like NICE? Moreover, what does the term imply about the basis for public decision-making? In recent years NICE has shifted away from this way of speaking, towards the language of 'principles'. Is this move insignificant - a case of a rose by any other name smelling as sweet - or does it signify a change in how NICE views its role as a decision-maker?

This article argues that while the demise of the idea of a 'social value judgement' is not before time, a shift in language is not by itself sufficient to resolve the limitations that have resulted from this conceptualisation of NICE's normative approach. We begin by offering some conjectural intellectual history about the origins of the term 'social value judgement', identifiying why some welfare economists under the influence of logical positivism thought it was the correct way to think about public policy choice. We go on to consider how NICE has used the term as a way of articulating its decision-making paradigm and point out the apparent gap that this has created - and which still exists - between NICE's formal expression of its approach and the approach that it actually adopts in practice. Finally, we suggest why this gap might be problematic for NICE's claims to act fairly and accountably on behalf of society and suggest how it might be narrowed by reframing NICE's approach around the idea of practical public reasoning.

\section{Health Economics: A Scion of Welfare Economics}

We are not aware of any work that has traced the history of the term 'social value judgement'. However, we conjecture that it is best understood against the background of developments in welfare economics of the midtwentieth century. By the 1930s, the economics of choice had turned ordinalist, shedding the psychological assumptions of utilitarianism that quantities of pleasure among different people could be compared with one another (Weale, 2020: Chapter 2). In the new welfare economics, which replaced the classical utilitarian approach, the welfare of different individuals could not be compared, and values were simply individuals' subjective preferences. Individuals' preferences could be self-interested, but they could also be ethical. For example, from a purely self-interested point of view a rich person might be opposed to the redistribution of income, but from an ethical point of view could favour greater equality. Each individual would thus have his or her own 'social welfare function'. As Harsanyi (1955: 309) put it, such a social welfare function was 'defined as an arbitrary mathematical function of economic (and other social) variables, of a form freely chosen according to one's personal ethical (or political) value judgments.' The problem was to find a method for determining a public or collective social welfare function from these individual welfare functions.

Arrow (1963) famously showed that, given a modest heterogeneity of preferences, this was not possible whilst satisfying certain intuitively reasonable conditions. No reasonable collective choice rule could be formulated if preferences over social alternatives were allowed to vary in any logically possible way. However, it was Harsanyi himself who offered one way out of the dilemma. He identified the ethical preferences that individuals 
have for society as a whole with those that any individual would hold from an impartial point of view, a point of view in which the individual has an equal chance of being anyone in society. Behind a thick veil of uncertainty, variation in preferences would be eliminated, and individuals' social preferences could be represented as the maximization of expected utility. Harsanyi went on to argue that, if we are also prepared to allow for comparisons of individual utility, then social welfare was at a maximum when it was the equally weighted sum of individual welfare (Harsanyi, 1955). The task of government was to implement these impartial ethical preferences. Unsurprisingly, when he came to defend the idea that the public social welfare function should be defined as the mathematical expectation of individual welfares, Harsanyi suggested, in the case of medicine, that priority should be given to those individuals who could benefit most from an intervention rather than those in greatest need, since that is the rule that would maximize utility (Harsanyi, 1975: 569).

In NICE's adoption of the idea of 'social value judgements', we are hearing the echoes of welfare economics at a particular stage of its development. Those echoes were distilled by Culyer when he introduced the term to

NICE at a Board meeting in 2000, to describe the value judgements made by NICE on society's behalf (personal communication). The effect of formulating normative judgements in these terms was to take on board the welfare economic assumption that various considerations of different kinds can be combined together to inform decisions about what is right for society in the allocation of healthcare resources, expressed as a collective choice rule for public policy.

\section{The NICE Paradigm}

In practice, the operation of the NICE paradigm focuses on the use of health technology assessment (HTA): a multidisciplinary process that uses explicit methods to determine the value of a health technology in order to inform decision-making (O’Rourke et al, 2020). HTA is a normative enterprise, in the sense in which economists distinguish 'normative economics' from 'positive economics'. Positive economics purports to explain why outcomes in the world are as they are, for example why there is a downward sloping demand curve for goods as prices rise. By contrast, normative economics is about shaping the world according to certain goals. In particular, if one wishes to get best 'value for money' from health care spending, then normative economics provides the techniques for operationalizing and acting on that general principle.

Echoing the utilitarianism from which it historically derived, NICE's framework makes the right policy that which is most productive of good. If good is measured by quality adjusted life-years (QALYs) - an imperfect proxy for 'health' - then the right way of judging whether an intervention is justified is to assess whether it produces a greater number of QALYs per unit cost than any alternative. Over time, if all new and existing interventions are appraised by this standard, then those that are more productive than alternatives will be retained, while those that are less productive will be eliminated. This approach to priority-setting has been helpfully compared to the systematic arrangement of books on a bookshelf (Culyer, 2016): books (that is, interventions) are added or removed based on their height (that is, their cost-effectiveness), with taller books preferred, until the cumulative width of all of the selected books (that is, their net cost) is approximately equal to the length of the bookshelf (that is, the total available budget). The selection of books has therefore been maximally productive as measured by height, as has the selection of interventions as measured by QALY gain. 
Over time NICE has developed this approach with some sophistication, recognising that simply maximizing QALYs is effective in promoting allocative efficiency, but does not capture everything that citizens deem valuable in the provision of healthcare. Thus, NICE's approach today incorporates many wider judgements about 'what is good for society' (Rawlins and Culyer, 2005) and attempts to apply and balance these through a deliberative approach to decision-making.

According to NICE's current articulation of its approach, the 'primary consideration' underpinning its decisions is 'overall population need', which 'means that sometimes we do not recommend an intervention because it does not provide enough benefit to justify its cost' (NICE, 2020). However, it acknowledges that 'other factors' aside from cost-effectiveness must also be taken into account, including the requirement to allocate resources fairly. Indeed, NICE recognizes that in some circumstances, the needs of particular groups might override those of the population as a whole, and has increasingly designated circumstances in which it considers this to be the case - for example, in considering treatments that extend life at the end-of-life, or treatments for very rare conditions (Charlton, 2019). Other normative considerations subscribed to by NICE include a requirement to avoid unwarranted discrimination, a desire to reduce health inequalities, and a commitment to 'support innovation in the provision and organization of health and social care services', although appraisal committees exercise considerable freedom in identifying what considerations are relevant to individual cases (NICE, 2020). Other factors are generally excluded from consideration, including the extent to which a person's condition might have been influenced by their behaviour, and an intervention's overall 'affordability' or impact on the NHS budget, although this position has been somewhat weakened in recent years (NICE, 2018; Charlton et al, 2017). Finally, alongside these substantive considerations NICE's approach recognizes several procedural elements, such as independence, transparency and inclusiveness, which it deems to be constitutive of a fair process and therefore necessary features of decision-making (NICE, 2020).

Traditionally, NICE has described these considerations as social value judgements 'that should, generally, be incorporated [...] and be applied' when developing NICE guidance (NICE, 2005). It has also come to present these as judgements made not only on society's behalf, as initially described by Culyer, but also as a reflection of 'society's expectations, preferences, culture and ethical principles' (NICE, 2020b). As such, NICE's formal expression of its approach suggests a mode of decision-making in which public preferences about various considerations are aggregated in order to identify the collective choice that will likely be most productive of good. In fact, the deliberative nature of NICE's approach grants appraisal committees considerable freedom to act as they see fit and in ways that do not straightforwardly reflect either the utilitarian goal of QALY maximisation or public preference about other sources of value in the provision of healthcare. NICE's reliance on the notion of the 'social value judgement' has therefore opened up a conceptual gap between the relatively simplistic articulation of its approach and the more sophisticated approach that it actually adopts in practice.

\section{A rose by any other name...}

It could be argued that all of this is just a matter of semantics, with little impact on how NICE goes about its business or the extent to which it can be considered to reach the 'right' answers about what technologies to recommend. However, as a public body responsible for making decisions on society's behalf, it is important that NICE is - and is seen to be - held accountable for those decisions. Historically, NICE has sought to ensure 'accountability for reasonableness' in part by being transparent about both its decisions and its grounds for 
reaching them (NICE, 2005; NICE, 2008). However, as NICE's approach has increased in complexity, the notion of the 'social value judgement' has proved insufficient to the task of adequately describing and justifying the normative basis for decision-making and may, in fact, have created a barrier to clearly conceptualising NICE's evolving approach and ensuring its continuing coherence. Some brief examples will serve to illustrate the point.

As has already been described, NICE's social value judgements include both substantive and procedural considerations. These provide legitimacy to NICE's decisions in different ways, either by providing the basis for a fair and accountable process, or by ensuring that the outcomes of this process can be accepted as reasonable. Both are necessary, neither are alone sufficient to secure legitimacy. Within each of these categories, a further distinction can be drawn between those values that take the form of goals, and those that take the form of constraints. Often, goals and constraints act in opposition to one another and must be balanced in order to realise the good associated with each: for example, the procedural goal of scientific rigour must be balanced against the procedural constraint of timeliness in deciding how comprehensive NICE should be in reviewing evidence of an intervention's effectiveness. Thus, the language of procedure and substance, and of goals and constraints, lends significant analytical power to considerations about the legitimacy of NICE's approach and the judgements reached in individual cases. This analytical power is unrealised in the grouping of these concepts together under the aggregative notion of 'social value judgements'.

The language of social value judgements also recognises no distinction between underlying values, the often complex value judgements that are derived from them and the policy instruments through which these are put into practice. For example, NICE's approach currently includes a 'modifier' that stipulates that interventions considered especially innovative can be recommended at a level of cost-effectiveness that would otherwise be deemed unacceptable (NICE, 2013; NICE, 2020). This value judgement - that, all else being equal, innovative technologies are more valuable than less innovative technologies - might conceivably be motivated by a range of underlying values, including the goal of allocative efficiency (on the basis that innovations that are costineffective in the short term may provide good value for money in the long term), that of maximising social utility (for example, by supporting economic growth via the life sciences industry), the constraint posed by equality of opportunity (given that innovative technologies often serve areas of unmet clinical need) or (perhaps more questionably) by recourse to the inherent value of scientific progress. This value judgement could also be put into practice via a variety of policy instruments, such as modification to the usual cost-effectiveness threshold, by accepting lower evidential standards for innovative technologies, or by taking a more generous approach to valuing the health benefits that accrue from the innovation. The current conceptualisation is insufficiently nuanced to articulate these different potential rationales for prioritising innovative interventions or the different ways in which this judgement might be realised. While this gives NICE increased scope to act flexibly in reaching its decisions, such ambiguity is to the detriment of transparency and perhaps also to the coherence of NICE policy in this area (Charlton and Rid, 2019).

Arguably most problematic for the 'social value judgement' is the erroneous impression it gives that NICE's value judgements reflect the views of society, overlooking the many ways in which individual subjective preferences might vary. While there might be broad societal agreement about 'fundamental' moral values such as justice and solidarity, there is rarely such consensus about the ways that these are rendered practical through 
more specified value judgements, which are significantly shaped by the social, cultural, religious and institutional features of particular populations. Even within a given population, diverse views often exist that cannot easily be aggregated in a single coherent position. For example, NICE's current approach values QALYs that are derived from life-extending treatments at the end-of-life more highly than QALYs derived from most other health technologies (NICE, 2016). However, evidence demonstrates that there is significant plurality in public views on this topic, with three distinct (and somewhat opposing) viewpoints each garnering substantial support (McHugh et al, 2015; McHugh et al, 2018). In situations such as this, NICE has no option but to settle on a normative position that many will not agree with, based on rationales that are not wholly 'social' in nature. The implication that all NICE value judgements are 'social' also ignores the role of other constraints on decision-making, such as legal requirements and political considerations, which do not always align with societal views. There is some evidence in the UK, for example, of public support for prioritising the health needs of children and young adults over those of older people (Erdem and Thompson, 2014; Petrou et al, 2013). However, such a value judgement is potentially counter to UK Equalities legislation, which generally treats age as a protected characteristic and thereby may preclude NICE from adopting such a position (HM Government, 2010).

Perhaps in recognition of some of these issues, NICE has begun to increasingly rely on the language of 'principles' rather than that of 'social value judgements', with a particular focus on the procedural principles that govern how decisions are reached (NICE, 2020; Littlejohns et al, 2019). However, this substitution of one term for another appears to be unaccompanied by any corresponding revision to either the conceptualisation used to describe NICE's normative approach, or the positivist assumption on which the notion of the 'social value judgement' is historically based. A situation prevails, therefore, in which the NICE paradigm is more sophisticated than NICE gives itself credit for, with the result that NICE continues to find itself without the necessary language to fully and accurately articulate the basis on which it reaches its decisions.

\section{Is There An Alternative?}

We have argued that NICE's policy paradigm contains an intellectual structure which implies that its decisions result from a coherent aggregation of individual preferences - that is, social value judgements. Foremost of these is the notion that the right decision is the one that is most productive of good, understood primarily through the proxy of QALY maximisation. In fact this paradigm has long been overtaken by NICE practice, which increasingly recognises other considerations, guided by the requirements of public and political accountability. As such, we suggest that a better characterisation of the enterprise in which NICE hopes to be engaged would be that of 'practical public reasoning'. It is practical, because the process is directed towards decision making. It is public in the sense that it is open to public inspection and is being done on behalf of the public. And it is reasoning, because the process takes the form of a set of value assumptions, joined together with empirical evidence in a chain of reasoning, leading to a conclusion.

Of these three elements, the most important in marking the change from speaking of social value judgements is the idea of reasoning. As we suggested in our conjectural intellectual history, the idea of social value judgements originates in a mid-twentieth century welfare economics heavily influenced by logical positivism, which saw values at best merely as an expression of feeling. Logical positivism pervaded economics at the time and still does in places. (Current sufferers are advised to seek qualified counselling.) But there are good reasons 
to abandon this positivist position. Policy principles, as assumptions, can be clearly articulated as sentences in the premisses of practical reasoning. For example, to say that healthcare should be cost-effective is not to express a subjective preference, but to propose a principle of public action, about which others can reason, in particular by considering the implications of the principle and whether those implications cohere with conscientious reflection. The same goes for other values and principles, whether they be non-discrimination, promoting innovation or prioritising the needs of those at the end of life.

A further advantage of speaking of practical public reasoning is that we are no longer constrained to brigade very different considerations under one heading. We can distinguish goals from constraints, and procedural values from substantive ones. We can be open about the basis for NICE's value judgements and the wide variety of social, ethical, legal and political considerations that it takes into account in adopting them. And in doing so, we create greater opportunity for such judgements to be subject to scrutiny and public debate. To be accountable is to set out an explanation and justification for one's decisions in such a way that others can see the chain of reasoning from assumptions to conclusions, even if those others disagree with the assumptions. We replace the idea of a monistic 'society' with the idea of citizens collectively reasoning through their different points of view, reaching at best only a partial consensus.

Perhaps most importantly, reframing the NICE enterprise in terms of practical public reasoning allows us to break free from the intellectual shackles of QALY maximisation. As the dominant social value judgement in NICE's approach, any departure from this goal is counted by some as a dilution of the pure milk of the health economics gospel; other considerations may modify, but they cannot compete on equal terms. As we have already noted, NICE itself broke free from this official doctrine long ago in reasoning its way to a more complex set of judgements, and its recent shift to the language of 'principles' perhaps signals a further step in this direction. The final stage of this journey is for NICE to acknowledge how far it has come and to find a better way to articulate the place that it has arrived at. 


\section{References}

Arrow, Kenneth J. (1963) Social Choice and Individual Values (New Haven: Yale University Press, 2nd ed).

Charlton, Victoria; Littlejohns, Peter; Kieslich, Katharina; Mitchell, Polly; Rumbold, Benedict; Weale, Albert; Wilson, James and Rid, Annette (2017) 'Cost effective but unaffordable: an emerging challenge for health systems', BMJ, 2017;356:j1402.

Charlton, Victoria (2019) 'NICE and Fair? Health Technology Assessment Policy Under the UK's National Institute for Health and Care Excellence, 1999-2018', Health Care Analysis, 28, pp. 193-227.

Charlton, Victoria and Rid, Annette (2019) 'Innovation as a value in healthcare priority-setting: the UK experience', Social Justice Research, 32, pp. 208-238.

Culyer, A (2016) 'Cost-effectiveness thresholds in health care: a bookshelf guide to their meaning and use', Health Economics, Policy and Law, 11, pp.415-432.

Erdem, Seda and Thompson, Carl (2014) 'Prioritising health service innovation investments using public preferences: a discrete choice experiment', BMC Health Services Research, 14:360.

Harsanyi, John C., (1955) 'Individualistic Ethics, and Interpersonal Comparisons of Utility', Journal of Political Economy, 63:4, pp. 309-21.

Harsanyi, John C. (1975) 'Can the Maximin Principle Serve as a Basis for Morality? A Critique of John Rawls's Theory', American Political Science Review, 69, pp. 594-606.

Her Majesty's Government, Equality Act 2010, Part 2, Chapter 1: Protected Characteristics [online]. Available at: https://www.legislation.gov.uk/ukpga/2010/15/part/2 [Accessed September 2020].

Littlejohns, Peter et al (2019) 'National Institute for Health and Care Excellence, social values and healthcare priority setting National Institute for Health and Care Excellence, social values and healthcare priority setting', Journal of the Royal Society of Medicine, 112(5), pp. 173-179.

McHugh, Neil; Baker, Rachel; Mason, Helen; Williamson, Laura; van Exel, Job; Deogaonkar, Rohan; Collins, Marissa and Donaldson, Cam (2015) 'Extending life for people with a terminal illness: a moral right and an expensive death? Exploring societal perspectives' BMC Medical Ethics, 16:14.

McHugh, Neil; van Exel, Job; Mason, Helen; Godwin, Jon; Collins, Marissa; Donaldson, Cam and Baker, Rachel (2018) 'Are life-extending treatments for terminal illnesses a special case? Exploringchoices and societal viewpoints' Social Science and Medicine, 198, pp. 61-69.

NICE (2005) Social value judgements: Principles for the development of NICE guidance, $1^{\text {st }}$ ed., NICE: London.

NICE (2008) Social value judgements: Principles for the development of NICE guidance, $2^{\text {nd }}$ ed., NICE: London.

NICE (2013) Guide to the methods of technology appraisal, NICE: London.

NICE (2016) PMG19 Addendum A - Final amendments to the NICE technology appraisal processes and methods guides to support the proposed new Cancer Drugs Fund arrangements, NICE: London.

NICE (2020a) 'The principles that guide the development of NICE guidance and standards', [online]. Available at https://www, nice.org.uk/about/who-we-are/our-principles [accessed September 2020].

NICE (2020b) ‘Glossary: Social value judgements', [online]. Available at https://www.nice.org.uk/Glossary?letter=S [accessed November 2020].

O'Rourke, Brian, Oortwijn, Wikja, Schuller, Tara, and the International Joint Task Group (2020) 'The new definition of health technology assessment: A milestone in international collaboration', International Journal of Technology Assessment in Health Care, 36:3, pp. 187-190.

Petrou, Stavros; Kandala, Ngianga-Bakwin; Robinson, Angela and Baker, Rachel (2013) 'A Person Trade-Off Study to Estimate Age-Related Weights for Health Gains in Economic Evaluation', PharmacoEconomics, 31, pp. 893-907.

Rawlins, Michael and Culyer, Anthony (2005) 'National Institute for Clinical Excellence and its value judgments', BMJ 329, pp. 224-227.

Weale, Albert (2020) Modern Social Contract Theory (Oxford: Oxford University Press). 